\title{
A comprehensive global oceanic dataset of helium isotope and tritium measurements
}

\author{
William J. Jenkins ${ }^{1}$, Scott C. Doney ${ }^{1, a}$, Michaela Fendrock ${ }^{1}$, Rana Fine ${ }^{2}$, Toshitaka Gamo ${ }^{3}$, \\ Philippe Jean-Baptiste ${ }^{4}$, Robert Key ${ }^{5}$, Birgit Klein ${ }^{6}$, John E. Lupton ${ }^{7}$, Robert Newton ${ }^{8}$, Monika Rhein ${ }^{9}$, \\ Wolfgang Roether ${ }^{9}$, Yuji Sano ${ }^{3}$, Reiner Schlitzer ${ }^{10}$, Peter Schlosser ${ }^{8, b}$, and Jim Swift ${ }^{11}$ \\ ${ }^{1}$ Department of Marine Chemistry and Geochemistry, Woods Hole Oceanographic Institution, \\ Woods Hole, Massachusetts 02543, USA \\ ${ }^{2}$ RSMAS, University of Miami, Miami, Florida 33149, USA \\ ${ }^{3}$ Atmosphere and Ocean Research Institute, The University of Tokyo, Kashiwa, Chiba 277-8564, Japan \\ ${ }^{4}$ LSCE, CEA-CNRS-UVSQ, CEA/Saclay, 91191 Gif-sur-Yvette CEDEX, France \\ ${ }^{5}$ Princeton University, Princeton, New Jersey, USA \\ ${ }^{6}$ BSH, 20359 Hamburg, Germany \\ ${ }^{7}$ NOAA Pacific Marine Environmental Laboratory, Newport, Oregon, USA \\ ${ }^{8}$ LDEO, Columbia University, Palisades, New York, USA \\ ${ }^{9}$ IUP, University of Bremen, 28359 Bremen, Germany \\ ${ }^{10}$ Alfred Wegener Institute, 27568 Bremerhaven, Germany \\ ${ }^{11}$ SIO, University of California San Diego, La Jolla, California, USA \\ ${ }^{a}$ now at: University of Virginia, Charlottesville, Virginia 22904, USA \\ bnow at: Arizona State University, Tucson, Arizona, USA \\ Correspondence: William J. Jenkins (wjenkins@whoi.edu)
}

Received: 29 October 2018 - Discussion started: 14 November 2018

Revised: 13 March 2019 - Accepted: 19 March 2019 - Published: 5 April 2019

\begin{abstract}
Tritium and helium isotope data provide key information on ocean circulation, ventilation, and mixing, as well as the rates of biogeochemical processes and deep-ocean hydrothermal processes. We present here global oceanic datasets of tritium and helium isotope measurements made by numerous researchers and laboratories over a period exceeding 60 years. The dataset's DOI is https://doi.org/10.25921/c1sn-9631, and the data are available at https://www.nodc.noaa.gov/ocads/data/0176626.xml (last access: 15 March 2019) or alternately http://odv.awi.de/data/ocean/jenkins-tritium-helium-data-compilation/ (last access: 13 March 2019) and includes approximately 60000 valid tritium measurements, 63000 valid helium isotope determinations, 57000 dissolved helium concentrations, and 34000 dissolved neon concentrations. Some quality control has been applied in that questionable data have been flagged and clearly compromised data excluded entirely. Appropriate metadata have been included, including geographic location, date, and sample depth. When available, we include water temperature, salinity, and dissolved oxygen. Data quality flags and data originator information (including methodology) are also included. This paper provides an introduction to the dataset along with some discussion of its broader qualities and graphics.
\end{abstract}




\section{Introduction}

The global oceanic distributions of tritium $\left({ }^{3} \mathrm{H}\right.$, a radioactive isotope of hydrogen with a half-life of 12.3 years), its daughter product ${ }^{3} \mathrm{He}$, and helium isotopes in general arise from the complicated interplay of ocean ventilation, circulation, and mixing, with the hydrologic cycle, air-sea exchange, and geological volatile input. Observations of the delivery of tritium to the ocean and its redistribution are a useful tool for diagnosing gyre- and basin-scale ventilation and circulation (Doney et al., 1992; Doney and Jenkins, 1994; Dorsey and Peterson, 1976; Dreisigacker and Roether, 1978; Fine and Östlund, 1977; Fine et al., 1987, 1981; Jenkins et al., 1983; Jenkins and Rhines, 1980; Michel and Suess, 1975; Miyake et al., 1975; Östlund, 1982; Sarmiento, 1983; Weiss and Roether, 1980; Weiss et al., 1979).

In shallow waters, away from seafloor hydrothermal vents, the combination of tritium and ${ }^{3} \mathrm{He}$ may be used to determine the time elapsed since a water parcel was at the sea surface, making it a useful tool for diagnosing ventilation and circulation on seasonal through decade timescales (Jenkins, 1987, 1998, 1977). The ingrowth and evasion of tritiugenic ${ }^{3} \mathrm{He}$ from the thermocline is also useful as a flux gauge for constraining the rate of nutrient return to the ocean surface (Jenkins, 1988; Jenkins and Doney, 2003; Stanley et al., 2015) as well as upwelling in coastal regions (Rhein et al., 2010). Finally, the distribution of helium isotopes in the deep sea provides important quantitative constraints on the impact of submarine hydrothermal venting on many elements because the global hydrothermal helium flux is well known (Bianchi et al., 2010; Holzer et al., 2017; Schlitzer, 2016). This makes ${ }^{3} \mathrm{He}$ useful as a flux gauge (German et al., 2016; Jenkins et al., 1978, 2018a; Lupton and Jenkins, 2017; Resing et al., 2015; Roshan et al., 2016). Consequently, there have been numerous measurements of these properties over the years, particularly under the aegis of major observational programs like GEOSECS (Bainbridge et al., 1987), TTO (Jenkins and Smethie, 1996), WOCE (http://www.nodc.noaa. gov/woce/wdiu/diu_summaries/whp/index.htm, last access: 1 April 2019), CLIVAR (http://www.clivar.org, last access: 1 April 2019), GO-SHIP (http://www.go-ship.org, last access: 1 April 2019), and GEOTRACES (http://www. geotraces.org, last access: 1 April 2019). It seems valuable to assemble all existing data, including those measured prior to and outside of these programs, along with appropriate metadata, in one place to facilitate further use and analysis. This is a report of these efforts.

\section{Methods}

\subsection{Tritium measurement methodology}

There are at present three distinct methods for the determination of tritium in water samples: direct measurement of tritium abundance by accelerator mass spectrometry (AMS), radioactive counting of tritium decay rate, and the daughter product $\left({ }^{3} \mathrm{He}\right)$ ingrowth method. The first method (AMS) has not been used for the measurement of environmental tritium levels but is better suited to measuring high tritium concentrations in small samples, largely for biomedical tracer research (Brown et al., 2005; Chiarappa-Zucca et al., 2002; Glagola et al., 1984; Roberts et al., 2000). The second method usually involves isotopic enrichment of hydrogen from the water samples, either by electrolysis (e.g., Östlund and Werner, 1962) or thermal diffusion (Israel, 1962) followed by low-level radioactive counting, either by liquid scintillation (Momoshima et al., 1983) or gas proportional counting (Bainbridge et al., 1961). Measurements are made relative to prepared standards (Unterweger et al., 1980), and accuracy appears to be limited by the reproducibility of the enrichment process to 3\%-10\% (Cameron, 1967).

The third method, ${ }^{3} \mathrm{He}$ ingrowth, is a three-step method. First, it involves degassing of a quantity $(\sim 1$ to $1000 \mathrm{~mL})$ of water to remove all dissolved helium. Second, the degassed water is stored in a helium leak-tight container (usually lowHe-permeability aluminosilicate glass or metal) for a period of several weeks to a year or more. Experience indicates that it is necessary to shelter the stored samples from cosmic rays since there is a latitude-dependent cosmogenic ${ }^{3} \mathrm{He}$ production rate that masquerades as "tritium signal" (Lott and Jenkins, 1998). Finally, the ingrown ${ }^{3} \mathrm{He}$ is extracted from the water sample and mass spectrometrically analyzed (Clarke et al., 1976; Ludin et al., 1997). The last method, although it involves a potentially lengthy incubation period, is chemically simpler and does not involve isotopic enrichment steps. As such, it offers intrinsically greater accuracy (limited by standardization of the mass spectrometer, typically better than $1 \%$ ) and a lower ultimate detection limit (Jenkins et al., 1983; Lott and Jenkins, 1998).

\subsection{Helium isotope measurement methodology}

Water samples are usually drawn from Niskin bottles into a helium leak-tight container either for shipboard (Lott and Jenkins, 1998; Roether et al., 2013) or shore-based gas extraction. The latter involves either clamped (Weiss, 1968) or crimped copper tubing (Young and Lupton, 1983). The extracted gases are subsequently purified and concentrated, usually cryogenically (Lott, 2001; Lott and Jenkins, 1984; Ludin et al., 1997), and expanded into a mass spectrometer for isotopic analysis. While time-of-flight mass spectrometry has been used (Mamyrin, 2001; Mamyrin et al., 1970), most oceanic helium isotope measurements have been made using multi-collector magnetic sector instruments (whereby ions are electrostatically accelerated and deflected by a magnetic field, e.g., Bayer et al., 1989; Clarke et al., 1969; Lott and Jenkins, 1998, 1984; Ludin et al., 1997). Measurements are typically standardized to marine air and corrected for any sample-size-dependent ratio effects determined by measurement of different-sized air aliquots. Depending on the 
amount of tritium in the water and the length of time a water sample is stored prior to gas extraction, it is generally necessary to correct the ${ }^{3} \mathrm{He} /{ }^{4} \mathrm{He}$ results for decay of tritium during storage. For very deep and old samples, e.g., at $3000 \mathrm{~m}$ in the North Pacific, where tritium concentrations are very low, this correction may be inconsequential.

\subsection{Helium and neon concentration measurements}

To make full use of the helium isotopic ratio measurements, one needs to know at least the concentration of helium in the samples as well. This allows investigators to calculate the actual concentration of both ${ }^{3} \mathrm{He}$ and ${ }^{4} \mathrm{He}$ in samples and, with some assumptions, to estimate the amount of nonatmospheric ${ }^{3} \mathrm{He}$ - whether it be from tritium decay or hydrothermal input - and ${ }^{4} \mathrm{He}$. The estimate can be further improved with knowledge of neon concentrations. Since neon is similar to helium in terms of its solubility in seawater and there are no known significant non-atmospheric sources of neon in the ocean, its concentration is a direct tracer of processes like air bubble injection at the sea surface. As an example, we show in Fig. 1 the relationship between the helium and neon saturation anomalies ${ }^{1}$ for approximately 2000 nearsurface samples. The saturation anomalies range from significantly below zero to as much as $10 \%-15 \%$. The negative values may arise from lower barometric pressures or air-sea disequilibrium during cooling. However, there may be systematic offsets due to laboratory standardization as well. The higher values may also reflect such biases but also may be due to air bubble entrapment during sampling at sea. The solid line in Fig. 1 represents a type-II linear regression of the data and has a slope of near unity, which is expected given the similarity of the two gases. However, the slope is greater than the precise ratio expected ( 0.8 to 0.9 depending on temperature) based on their solubilities and atmospheric abundances, possibly due to differing air-sea exchange rates. Consideration must be given to these and other factors when using this data (e.g., Fuchs et al., 1987; Roether et al., 1998).

Helium and neon concentration measurements are typically made by mass spectrometric peak height manometry, that is, by comparison of major isotope ion currents $\left({ }^{4} \mathrm{He}^{+}\right.$ and ${ }^{20} \mathrm{Ne}^{+}$) between the unknown to helium and neon derived from an aliquot of marine air. The air aliquot size is determined from a knowledge of the barometric pressure, relative humidity, and temperature at which the previously evacuated air standard reservoir was filled and the volume of the aliquot. Generally the ion current is assumed to be a linear function of the sample size (number of atoms) over some narrow range but also can be corrected by construction

\footnotetext{
${ }^{1}$ The saturation anomaly of a gas is the percent deviation of the measured concentration relative to the expected concentration of the sample in equilibrium with air at one atmosphere, for example, as defined by $\Delta \mathrm{He}=100\left(C / C^{*}-1\right)$, where $C^{*}$ is the solubility equilibrium concentration at the temperature and salinity of the sample.
}

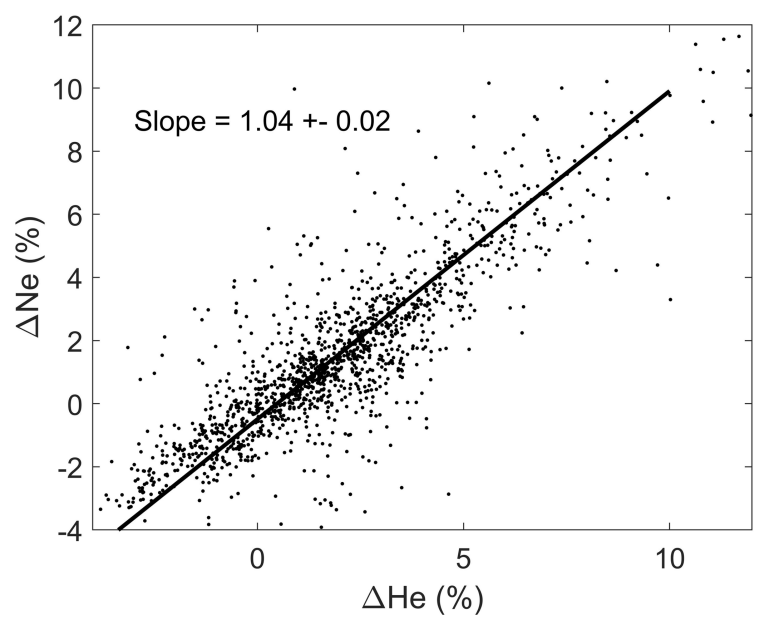

Figure 1. A scatter plot of helium and neon saturation anomalies for nearly 2000 near-surface $(<20 \mathrm{~m}$ depth) samples from the dataset. The solid line is a type-II linear regression of the data.

of a standard curve using different sized aliquots. Some measurements (notably the GEOSECS expedition) were made by splitting the gas extracted from the water sample and measuring the helium and neon contents separately using isotope dilution (with ${ }^{3} \mathrm{He}$ and ${ }^{22} \mathrm{Ne}$ spikes).

\subsection{Data organization}

We have compiled a comprehensive dataset consisting of helium isotope and tritium measurements in oceanic waters made by numerous laboratories over the past 6 decades. The dataset includes $\sim 60000$ tritium and $\sim 63000$ helium isotope measurements, $\sim 57000$ dissolved helium concentrations, and $\sim 34000$ dissolved neon concentrations in ocean water taken from 1952 to 2015 (for tritium) and from 1967 to 2015 for helium. In addition to "spot sampling", there are $\sim 380$ cruises, with sampling from $>5400$ locations for tritium and $\sim 5600$ locations for helium. The helium data are from 8 different laboratories and the tritium data from 15 laboratories worldwide. In addition to including measurement uncertainties, a data quality flag, and data source, each data point is accompanied by location (latitude, longitude, depth) and time (decimal year) of sampling. When available, water temperature, salinity, and dissolved oxygen measurements are included.

A number of the earliest measurements were obtained from publications. In those cases, the publication source is given. If the data were transcribed from tables, the table number and page is also given. In the event that the data were only available graphically, a computer program to digitize the data from plots was used, and in the rare cases in which graph quality was sufficiently poor to degrade the precision of the data, the uncertainties were commensurately increased to reflect it. Where data had been assigned a Digital Object Identifier (DOI), this is also included. 
Table 1. Fields (columns) in the main data table.

\begin{tabular}{|c|c|c|}
\hline Field name & Field type & Field description \\
\hline ExpoCode & Short text & Unique string identifying cruise/expedition \\
\hline Sect_ID & Short text & String identifying Ocean Section (WOCE, CLIVAR, or GEOTRACES) \\
\hline Station & Short text & Station name or number \\
\hline CastNo & Short text & Cast name or number at that station \\
\hline Bottle & Short text & Bottle name or number on that cast \\
\hline StaDate & Number & Decimal year of sampling \\
\hline Latitude & Number & North latitude in decimal degrees (from -90 to +90 ) \\
\hline Longitude & Number & East longitude in decimal degrees (from -180 to +180 ) \\
\hline StaDepth & Number & Bottom depth at station location in meters \\
\hline Pressure & Number & Bottle depth (actually pressure) measured in dbar \\
\hline Temperature & Number & In situ temperature in degrees centigrade \\
\hline Temperature_Flag & Integer & Temperature quality flag (see QF table) \\
\hline Salinity & Number & Sample salinity in PSU \\
\hline Salinity_Flag & Integer & Salinity quality flag (see QF table) \\
\hline Oxygen & Number & Dissolved oxygen in $\mu \mathrm{mol} \mathrm{kg} \mathrm{kg}^{-1}$ \\
\hline Oxygen_Flag & Integer & Dissolved oxygen flag (see QF table) \\
\hline Tritium & Number & Tritium in TU at time of sampling \\
\hline Tritium_Error & Number & Uncertainty in TU at time of sampling \\
\hline Tritium_Flag & Integer & Tritium quality flag (see QF table) \\
\hline Tritium_PI & Short text & Principle investigator or measurer of tritium \\
\hline Tritium_PI_Inst & Short text & Institution or laboratory where tritium was measured \\
\hline Tritium_Method & Short text & Short descriptor of tritium sampling/analysis method \\
\hline DelHe 3 & Number & Helium isotope ratio anomaly relative to atmosphere in percent \\
\hline DelHe3_Error & Number & Uncertainty in helium isotope ratio anomaly \\
\hline DelHe3_Flag & Integer & Helium isotope ratio anomaly quality flag (see QF table) \\
\hline Helium & Number & Dissolved helium concentration in $\mathrm{nmol} \mathrm{kg}^{-1}$ \\
\hline Helium_Error & Number & Uncertainty in dissolved helium concentration in $\mathrm{nmol} \mathrm{kg}^{-1}$ \\
\hline Helium_Flag & Integer & Dissolved helium quality flag (see QF table) \\
\hline Neon & Number & Dissolved neon concentration in $\mathrm{nmol} \mathrm{kg}^{-1}$ \\
\hline Neon_Error & Number & Uncertainty in dissolved neon concentration in $\mathrm{nmol} \mathrm{kg}^{-1}$ \\
\hline Neon_Flag & Integer & Dissolved neon quality flag (see QF table) \\
\hline Helium_PI & Short text & Principle investigator or measurer of helium (and neon) \\
\hline Heliulm_PI_Ins & Short text & Institution or laboratory where tritium was measured \\
\hline Helium_Method & Short text & Short descriptor of helium sampling/analysis method \\
\hline Reference_Code & Short text & Data origin or link to paper discussing data \\
\hline Reference_Source & Short text & Data source within reference (e.g., table, figure) if relevant \\
\hline DOI & Short text & Digital Object Identifer of original dataset (if existing) \\
\hline Comment & Short text & Additional information or comments \\
\hline Record_ID & Long integer & Unique record identifier number \\
\hline
\end{tabular}

The dataset (provided in several digital formats described below) consists of three tables. The REFERENCES table is a list of the data sources keyed by the text variable "Reference_Code" found in the main data table. This provides attribution or more information regarding the data origin. The METHODS table provides a more complete description of the fields "Tritium_Method" and "Helium_Method" in the main data table. This is intended to provide useful interpretive information regarding how the sampling and/or measurements were accomplished. The main data table fields are described in Table 1. Most data fields have an associated quality flag field whose meaning is summarized in Table 2. Following WOCE ocean data convention, normal acceptable data are associated with a quality flag of 2 , whereas questionable data have a flag of 3 . Results obtained by averaging two or more replicates are signified with a flag of 6 . When fields are missing for a given record, the data are entered as -999 and the corresponding quality flag is 9. The tritium, helium, helium isotope, and neon data also have an associated uncertainty field (e.g., "Tritium_Error"), which is the estimated uncertainty in the data points. This is either provided by the data measurer or an estimate based on described procedures and can vary greatly between methods and laboratories, so the user is advised to be aware of this value. 
Table 2. Quality flag meaning.

\begin{tabular}{ll}
\hline $\begin{array}{l}\text { Quality flag } \\
\text { number }\end{array}$ & Meaning \\
\hline 2 & Normal data, no problems reported \\
3 & $\begin{array}{l}\text { Questionable data: may not fit profile } \\
\text { or some other doubt }\end{array}$ \\
6 & Average of two or more measurements \\
9 & Missing (null) data \\
\hline
\end{tabular}

In the spirit of the WOCE, CLIVAR, and GO-SHIP ${ }^{2}$ convention, the combination of ExpoCode, Station, CastNo, and Bottle should uniquely define a sample. That is, no two data records should have the same combination of these values. This has been followed with most of the information here: when a sample's station, cast, or bottle number were not provided (in the case of literature data), arbitrary but unique numbers were assigned. In order to supplement this identification, we added a unique integer record ID number.

\subsection{Data formats and availability}

The dataset's DOI is https://doi.org/10.25921/c1sn-9631 (Jenkins et al., 2018b). The data are available for download from the U.S. National Oceanic and Atmospheric Administration's National Centers for Environmental Information website at https://www.nodc.noaa.gov/ocads/data/ 0176626.xml or alternately http://odv.awi.de/data/ocean/ jenkins-tritium-helium-data-compilation/in a number of formats. For maximum flexibility, we suggest one of the following three database formats: Microsoft Access ${ }^{\circledR}$, PostgreSQL, or ODV (Ocean Data View). In addition, the three tables are available as four files (the main data table is split into two to avoid spreadsheet row-number limitations) in Microsoft Excel $^{\circledR}$ or as comma-separated plain text files. The data are also available in NetCDF format. Finally, the data table is available for download as a MATLAB ${ }^{\circledR}$ binary data file.

\section{Scope and nature of the dataset}

We provide some graphics to indicate the scope and nature of the data holdings. These include time histories of analyses per year for both types of measurements (Fig. 2) and maps of sampling locations (Fig. 3). The intent is to provide a broad overview of the character of the datasets while not overinterpreting its details and features.

\footnotetext{
${ }^{2}$ WOCE is the World Ocean Circulation Experiment (e.g., see https://www.nodc.noaa.gov/woce/, last access: 1 April 2019), CLIVAR is the Climate and Ocean - Variability, Predictability, and Change (e.g., see http://www.clivar.org/about, last access: 1 April 2019), and GO-SHIP is the Global Ocean Ship-Based Hydrographic Investigations Program (see http://www.go-ship.org/, last access: 1 April 2019).
}
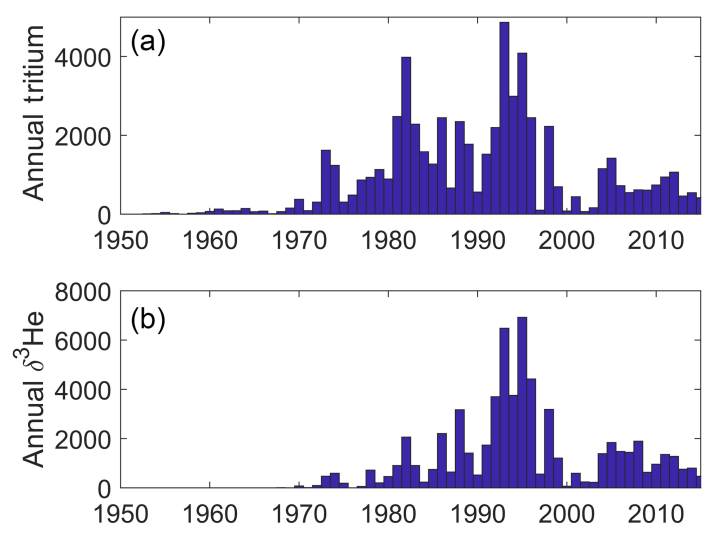

Figure 2. Time distributions of annual tritium (a) and helium (b) measurements.

The temporal distribution of oceanic tritium measurements begins in the early 1950s with the development of enrichment and counting capabilities suitable for environmental levels, the recognition of the existence of cosmogenic tritium production (Cornog and Libby, 1941; Currie et al., 1956; Grosse et al., 1951; Kaufman and Libby, 1954; Libby, 1946), and the desire to measure its distribution in the hydrologic cycle. The advent of atmospheric thermonuclear tests in the 1950s and early 1960s dwarfed the natural global inventory (Weiss and Roether, 1980), which motivated an increase in oceanic measurements in the 1960s. The initiation of global ocean chemistry, hydrographic, and tracer survey efforts (especially GEOSECS $^{3}$ ) further increased this activity. A final boost to tritium measurement rates occurred with the development of the ${ }^{3} \mathrm{He}$ regrowth method (Clarke et al., 1976) coupled with even more ambitious global surveys (such as WOCE, CLIVAR, and GO-SHIP).

The helium sampling time history was basically initiated and motivated by the discovery of primordial ${ }^{3} \mathrm{He}$ injection into the deep waters (Clarke et al., 1969), which drove the inclusion of helium isotope measurements in the GEOSECS program. It was quickly realized that the existence of tritiugenic ${ }^{3} \mathrm{He}$ (that produced by the in situ decay of tritium) offered the potential for a dating tool as well (Jenkins et al., 1972; Jenkins and Clarke, 1976), which spurred on continued helium isotope measurements in the global surveys. These were enabled by a number of laboratories coming "online" in the 1970s and 1980s.

The tritium and helium sampling locations shown in Fig. 3 are dominated by the global survey programs' cruise tracks, but also include a number of ocean island monitoring sites (especially for tritium). One difference in the two maps is the extra tritium sampling in the Arctic, perhaps largely driven by H. Göte Östlund's motivation to exploit this isotope's potential in studying the Arctic fresh water system (Östlund, 1982).

\footnotetext{
${ }^{3}$ GEOSECS is the Geochemical Ocean Sections Survey.
} 

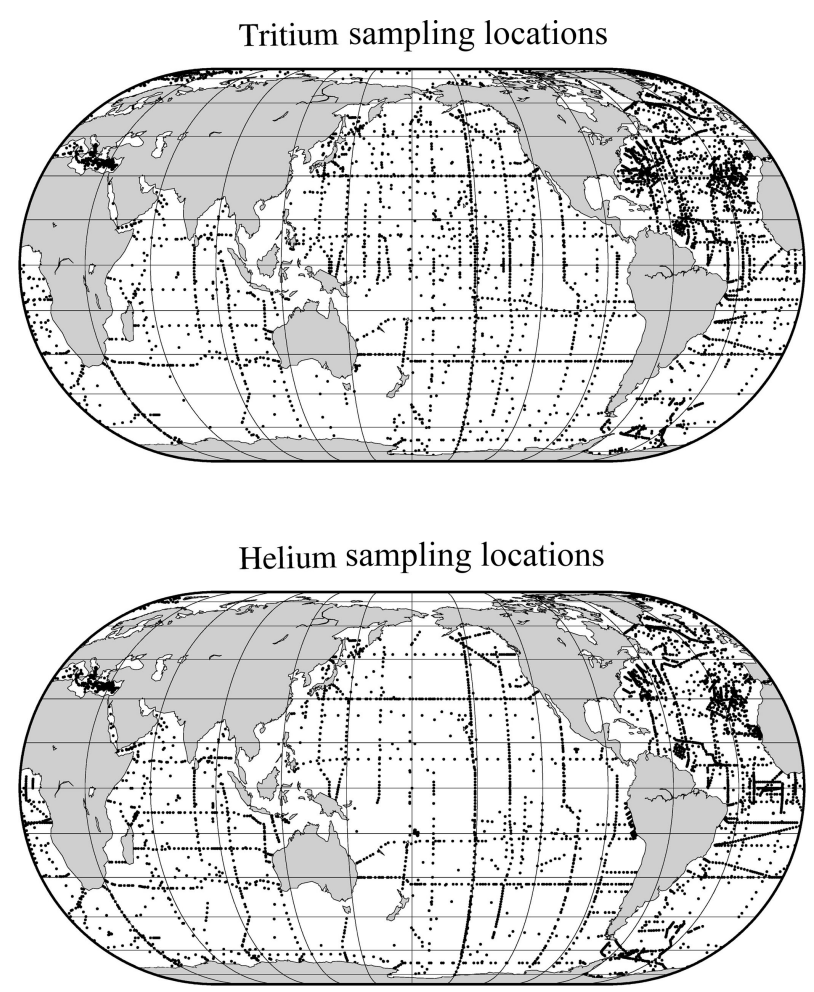

Figure 3. Tritium and helium sample locations.

It is well known that the delivery of bomb tritium to the ocean was a reflection of the distribution of the atmospheric tests and occurred in two principle modes: a dominant pulse-like injection in the Northern Hemisphere and a much smaller more "diffuse" input into the Southern Hemisphere (Doney et al., 1992). The former mode was dominated by the early 1960s American and USSR tests that occurred just prior to the 1963 Partial Test Ban Treaty, while the southern hemispheric tests were carried out predominantly by the UK and France. Weiss and Roether (1980) estimated the delivery of approximately $1500 \mathrm{GCi}$ to the Northern Hemisphere and 480 GCi to the Southern Hemisphere by the end of 1972. The latitudinal trends can be seen in Fig. 4, which is a plot of near-surface ( $<50 \mathrm{~m}$ depth) water tritium concentrations vs. time for a number of latitude bands. Most striking is the northward increase in the concentration ( $y$-axis) ranges. The time-latitude trends in Fig. 4 reflect this globally asymmetric delivery, but much of the structure caused by regional variations in atmospheric input and ocean circulation may be masked due to conflating major ocean basins in the groupings.

As a transient tracer, tritium offers an opportunity to visualize the ventilation of deep waters on decade to century timescales. Benchmark observations of water column tritium concentrations during the GEOSECS Atlantic Expedition reveal North Atlantic deep water formation in a graphic manner (Östlund et al., 1974). The evolution of the tritium dis- tributions is also valuable as they penetrate the subtropical thermocline and also intermediate and deep waters. Figure 5 shows four snapshots of tritium distributions on a section along approximately $52^{\circ} \mathrm{W}$ in the North Atlantic between the South American and North American coasts (see map inset). Tritium concentrations are decay-corrected to a common midpoint in time (1997) for comparison. While the last three occupations are conveniently along the same cruise track (courtesy of WOCE, CLIVAR, and GO-SHIP), the first is a composite from several cruises of opportunity taken over an approximately 1-year period at roughly the same longitude. One can readily see the downward propagation and ultimate dispersion of the bomb tritium pulse within the main thermocline (the upper $1000 \mathrm{~m}$ ), and the progressive ingrowth of tritium in the intermediate layer (1500-2500 m depth) and in the bottom layers $(\sim 4000 \mathrm{~m})$ is striking. One can also see the repartitioning of tritium inventories in the upper waters, both due to vertical exchange and ventilation but also due to the continued accumulation of this bomb fallout isotope at subtropical latitudes (similar to bomb radiocarbon, as observed by Broecker et al., 1995) from more tritium-rich waters to the north.

Equally important is evidence of the southward propagation of the transient tracer along the deep western boundary current system from Nordic and Labrador seas (Doney and Jenkins, 1994). This first appears in 1982 at the northern end of the section between 3000 and $4000 \mathrm{~m}$ depth near the bottom of the continental slope. As time progresses, it grows in at intermediate $(\sim 1500 \mathrm{~m})$ and deeper $(3500-4000 \mathrm{~m})$ depths at the southern end. This clearly marks the net advective timescales for the deep- and intermediate-depth western boundary currents.

Figure 6 shows the corresponding helium isotope anomaly distribution for the tritium sections. Interpretation of the helium isotope ratio anomaly is a little more complicated than the invasion of bomb tritium, but the buildup of tritiugenic ${ }^{3} \mathrm{He}$ within the main thermocline is an important diagnostic of vertical transport for the subtropical main thermocline. Its retention and back-flux to the ocean surface is a uniquely valuable transient tracer observation, one that parallels the buildup and reflux of inorganic nutrients in the thermocline (e.g., nitrate and phosphate) but in a quantifiably defined manner. Observations of surface water ${ }^{3} \mathrm{He}$ excesses (not shown here) have been used as flux gauges to quantify/constrain regional-scale new production rates (Jenkins, 1988; Jenkins and Doney, 2003; Stanley et al., 2015) as well as upwelling rates (Rhein et al., 2010).

We also include a time series (plotting only the upper 2000 dbar in Fig. 7) for stations within $200 \mathrm{~km}$ of Bermuda $\left(32.3^{\circ} \mathrm{N}, 64.7^{\circ} \mathrm{W}\right)$ in the subtropical North Atlantic, which highlights some high temporal resolution features in the penetration of tritium into and ingrowth of ${ }^{3} \mathrm{He}$ within the main thermocline and intermediate waters at one location.

Perhaps the most notable features of the oceanic distribution of the helium isotope ratio anomaly are the large 

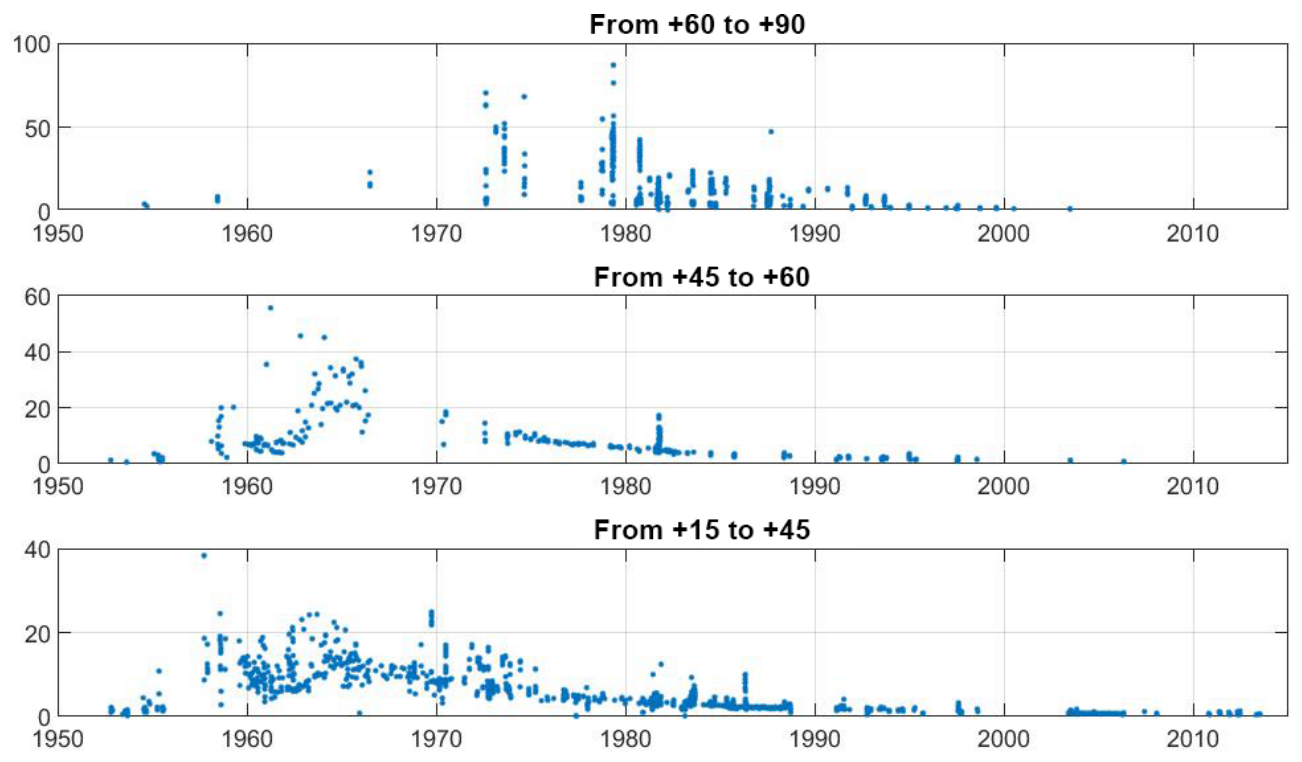

From -5 to +15
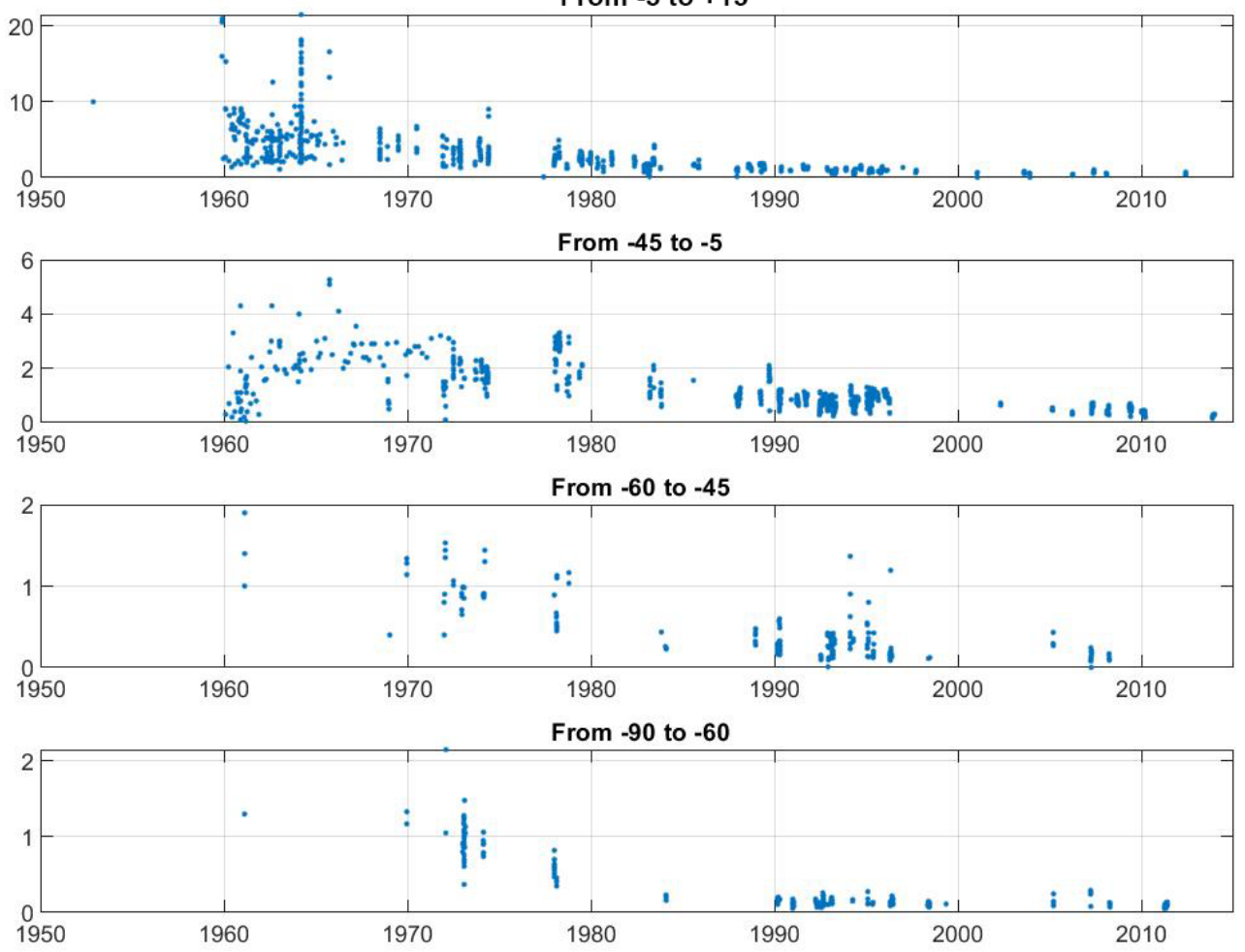

Figure 4. Global ocean surface water (depth $<50 \mathrm{~m}$ ) tritium concentrations (in TU) for selected latitude bands.

tongues emanating from mid-ocean ridges and other volcanic edifices on the sea floor (see the map of the helium isotope ratio anomaly at $2500 \mathrm{~m}$ depth in Fig. 8), driven by the roughly order-of-magnitude higher ${ }^{3} \mathrm{He} /{ }^{4} \mathrm{He}$ ratio in the earth's mantle compared to the atmosphere (Clarke et al., 1969; Kurz and Jenkins, 1981; Kurz et al., 1982; Lupton and Craig, 1975). It was in fact the initial discovery (Clarke et al., 1969) that sparked continued interest in the oceanic distribution of helium isotopes. In contrast, one sees a dif- ferent pattern deeper down ( $4000 \mathrm{~m}$, in Fig. 9), where one sees the relatively ${ }^{3} \mathrm{He}$-impoverished bottom waters flowing northward into the abyssal Pacific. The ongoing survey of deep helium features on both basin and regional scales continues today, particularly in support of "flux gauge" studies of other trace elements and metals influenced by seafloor hydrothermal processes (e.g., Jenkins et al., 2018a; Resing et al., 2015; Roshan et al., 2016). These are based on recent model-based estimates of the global flux of hydrother- 


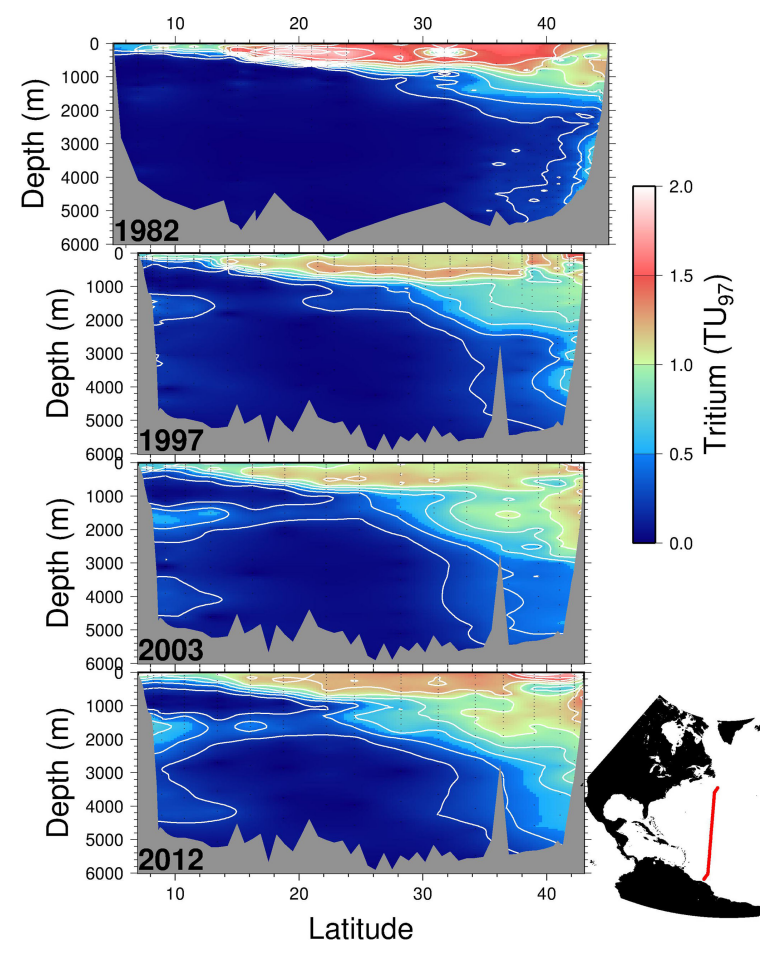

Figure 5. Four meridional tritium sections along roughly $52^{\circ} \mathrm{W}$ in the North Atlantic taken in 1982, 1997, 2003, and 2012. The tritium concentrations have been decay-corrected to a common time (1 January 1997) for comparison. Contour intervals are 0.2 TU97, and measurement uncertainties are of order $0.01 \mathrm{TU}_{97}$ or better. Due to differences in cruise tracks, the topography for the $1982 \mathrm{oc}-$ cupation differs from the others.

mal ${ }^{3} \mathrm{He}$, which center around $550 \mathrm{~mol} \mathrm{yr}^{-1}$ (Bianchi et al., 2010; Holzer et al., 2017; Schlitzer, 2016). This estimate can be usefully compared to the expected global flux of tritiugenic ${ }^{3} \mathrm{He}$. The global tritium production by atmospheric nuclear weapons tests has been estimated to be of order $3 \mathrm{GCi}$ (Weiss and Roether, 1980, corrected from 1972 to 1963) to 5 GCi (Michel, 1976). Given that the bulk of the tritium "impulse" entered the hydrologic system and subsequently the oceans within a decade or so, one can argue that the production rate of tritiugenic ${ }^{3} \mathrm{He}$ was of order $3000 \mathrm{~mol} \mathrm{yr}^{-1}$ in the mid-1970s. By the mid-1990s, this would be of order $1000 \mathrm{~mol} \mathrm{yr}^{-1}$. Separating the two "types" of ${ }^{3} \mathrm{He}$ (tritiugenic vs. primordial) in the Northern Hemisphere, where the bulk of the tritium delivery occurred (Doney et al., 1992; Weiss and Roether, 1980), is relatively simple in that the former appears largely at the sea surface, and the latter is concentrated in older, deeper waters. The separation in the Southern Hemisphere is not so simple.

\section{Data availability}

Information about the underlying dataset can be found in Sect. 2.5.

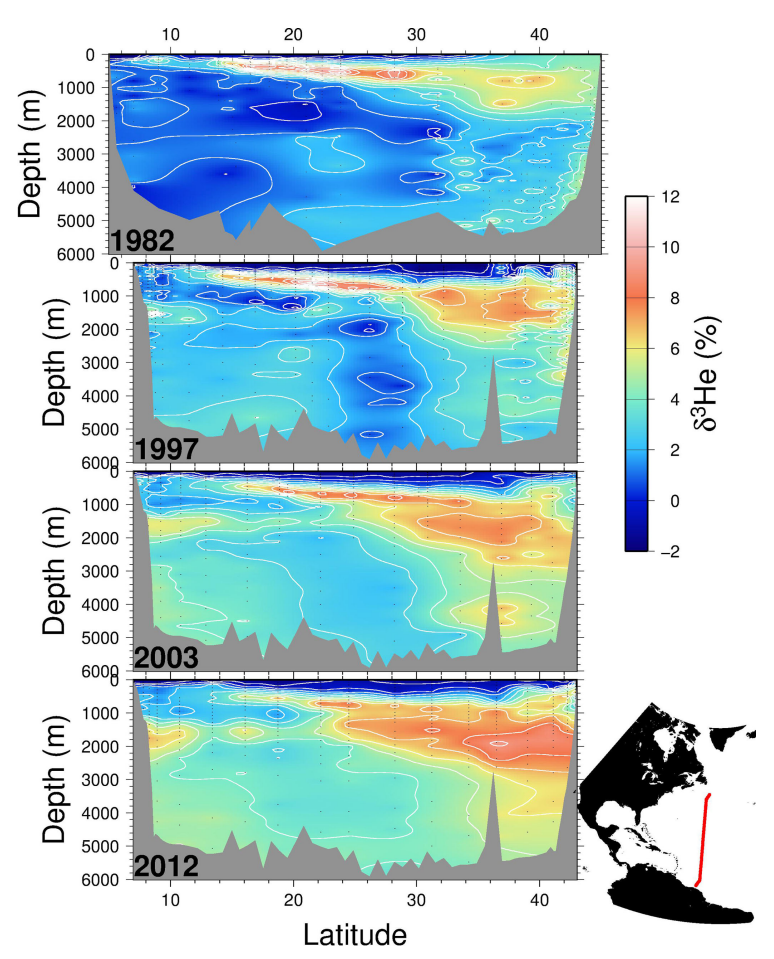

Figure 6. Four meridional $\delta^{3} \mathrm{He}$ sections along roughly $52^{\circ} \mathrm{W}$ in the North Atlantic taken in 1982, 1997, 2003, and 2012. Contour intervals are $1 \%$, and measurement uncertainties are $0.15 \%$. Due to differences in cruise tracks, the topography for the 1982 occupation differs from the others.

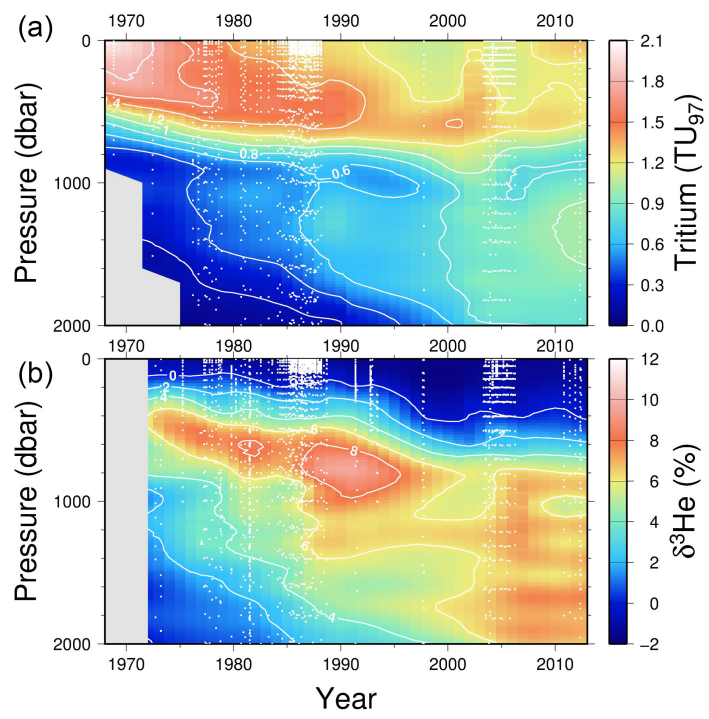

Figure 7. A time series of tritium (upper) and helium isotope measurements in the vicinity of Bermuda (North Atlantic). Tritium values have been decay-corrected to a common time (1 January 1997). White dots indicate sampling depths and times. 


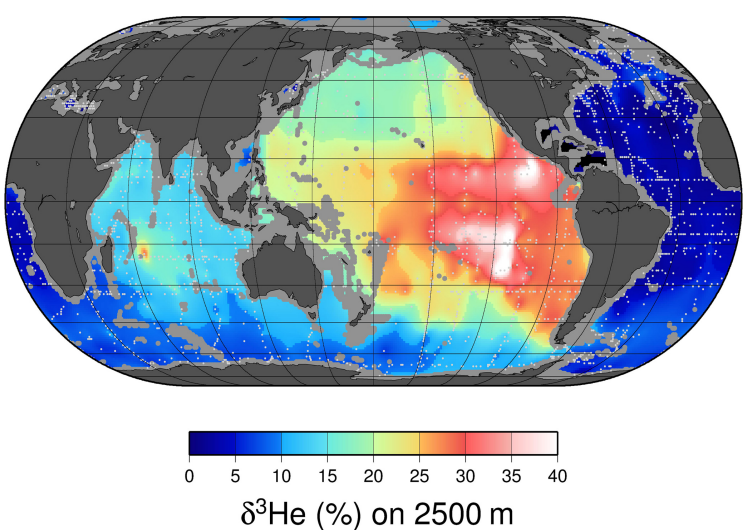

Figure 8. A map of $\delta^{3} \mathrm{He}$ values at approximately $2500 \mathrm{~m}$ depth. The values plotted are simply an average of all measurements within a $1^{\circ}$ square between 2250 and 2750 dbar. Depths shallower than $2500 \mathrm{~m}$ are masked in gray, and sampling locations are indicated by light gray dots.

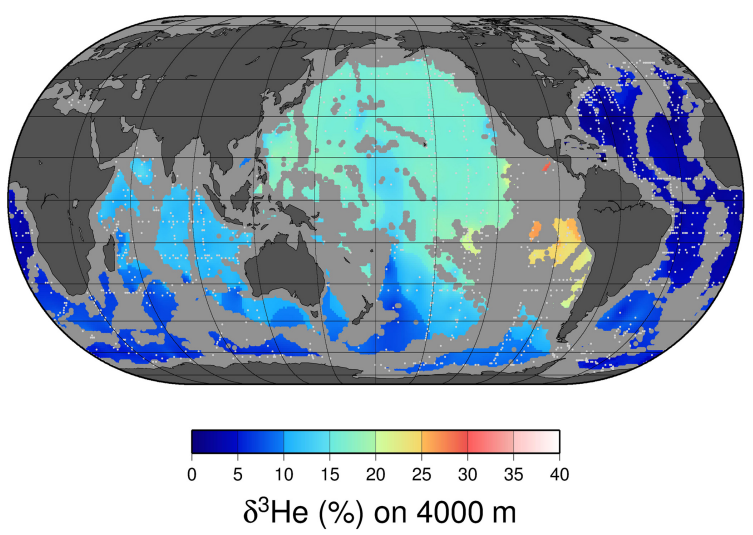

Figure 9. A map of $\delta^{3} \mathrm{He}$ values at approximately $4000 \mathrm{~m}$ depth. The values plotted are simply an average of all measurements within a $1^{\circ}$ square between 3750 and 4250 dbar. Depths shallower than $4000 \mathrm{~m}$ are masked in gray, and sampling locations are indicated by light gray dots.

\section{Contributors and pioneers}

This dataset represents the hard work over many decades of numerous individuals that are not included in the authorship list of this paper. We list their names and affiliations at the time of their contributions in Table 3. The list focuses on those who made the measurements rather than those who may have used the data. We apologize if there are others that we may have missed in this list.

We also would like to recognize that the ability to make the measurements presented in this dataset was a consequence of the pioneering work of more than a few inventive and talented individuals. While space does not permit mentioning them all here, we felt it appropriate to highlight a pair of pioneering scientists who conducted landmark studies on ocean tritium and ${ }^{3} \mathrm{He}$ measurements.
Table 3. Contributing analysts that are not authors on this paper.

\begin{tabular}{|c|c|}
\hline Arnold E. Bainbridge & UCSD, La Jolla, CA, USA \\
\hline Reinhold Bayer & U. Heidelberg, Heidelberg, Germany \\
\hline Friedrich Begemann & U. Chicago, Chicago, IL, USA \\
\hline Ulrich Beyerle & ETH, Zurich, Switzerland \\
\hline Wallace S. Broecker & LDEO, Pallisades, NY, USA \\
\hline Martin Butzin & University of Bremen, Bremen, Germany \\
\hline William Brian Clarke & McMaster University, Hamilton, ON, Canada \\
\hline K. O. Dockins & UCSD, La Jolla, CA, USA \\
\hline H. Gorman Dorsey & RSMAS, Miami, FL, USA \\
\hline Eric Eriksson & IMS, Stockholm, Sweden \\
\hline Elise Fourré & CEA-Saclay, France \\
\hline Bruno J. Giletti & LDEO, Pallisades, NY, USA \\
\hline Aristid von Grosse & RITU, Philadelphia, PA, USA \\
\hline J. R. Harries & Australian AEC, Sutherland, NSW, Australia \\
\hline T. Kaji & Kyushu University, Fukuoka, Japan \\
\hline Sheldon Kaufman & U. Chicago, Chicago, IL, USA \\
\hline J. Laurence Kulp & LDEO, Pallisades, NY, USA \\
\hline Willard F. Libby & U. Chicago, Chicago, IL, USA \\
\hline Dempsey E. Lott III & WHOI, Woods Hole, MA, USA \\
\hline Andrea Ludin & LDEO, Pallisades, NY, USA \\
\hline Liliane Merlivat & Sorbonne University, Paris, France \\
\hline Robert Michel & UCSD, La Jolla, CA, USA \\
\hline Yasuo Miyake & GRA, Tokyo, Japan \\
\hline Karl-Otto Munnich & U. Heidelberg, Heidelberg, Germany \\
\hline Alfred O. Nier & U. Minnesota, Minneapolis, MN, USA \\
\hline Masami Nonaka & IPRC \& SOES, Tokyo, Japan \\
\hline Hans Göte Östlund & RSMAS, Miami, FL, USA \\
\hline Clare F. Postlethwaite & NOC-SOES, Southampton, UK \\
\hline Paul D. Quay & University of Washington, Seattle, WA, USA \\
\hline Rachel S. H. R. Stanley & WHOI, Woods Hole, MA, USA \\
\hline Sheila Stark & NOC-SOES, Southampton, UK \\
\hline Reiner Steinfeldt & IUP, University of Bremen, Germany \\
\hline Hans E. Suess & UCSD, La Jolla, CA, USA \\
\hline Jurgen Súltenfuss & IUP, University of Bremen, Germany \\
\hline Naoto Takahata & ORI, University of Tokyo, Tokyo, Japan \\
\hline A. Tamuly & University of Quebec, Rimouski, PQ, Canada \\
\hline C. B. Taylor & INS, Lower Hutt, New Zealand \\
\hline Zafer Top & RSMAS, Miami, FL, USA \\
\hline Tom Torgersen & WHOI, Woods Hole, MA, USA \\
\hline Kim A. Van Scoy & RSMAS, Miami, FL, USA \\
\hline Carolyn Walker & WHOI, Woods Hole, MA, USA \\
\hline Wolfgang Weiss & U. Heidelberg, Heidelberg, Germany \\
\hline Peter M. Williams & UCSD, La Jolla, CA, USA \\
\hline
\end{tabular}

\subsection{W. Brian Clarke (1937-2002)}

Although not the first to measure ${ }^{3} \mathrm{He} /{ }^{4} \mathrm{He}$ in the environment (that was done by Aldrich and Nier, 1948), Clarke made the first reported helium isotope measurements in seawater (Clarke et al., 1969). He made his first measurements using a modified single stage magnetic sector, single collector mass spectrometer to a precision of about $2 \%$. Clarke developed the first compact all-metal branch tube mass spectrometer specifically designed to make ${ }^{3} \mathrm{He} /{ }^{4} \mathrm{He}$ measurements ultimately to a precision of $0.1 \%$ to $0.2 \%$. At the time, conventional wisdom dictated that such measurements (let alone precision measurements) were not possible with a single stage magnetic sector instrument for such high $\left(10^{6}\right)$ abundance ratios, but Clarke forged ahead anyway. He initially constructed two instruments in the early 1970s, using 
one at McMaster University in Hamilton, Ontario, Canada, and setting the other machine up at the Scripps Institute of Oceanography in La Jolla, CA, USA, for Harmon Craig and John Lupton. These instruments were used in support of the GEOSECS program and subsequently for a wide variety of other research projects. One of his students (William J. Jenkins) moved to the Woods Hole Oceanographic Institution in Woods Hole, MA, USA, where he extended Clarke's design to construct three other instruments. A post-doctoral investigator from his laboratory (Zafer Top) moved to RSMAS at the University of Miami and constructed a similar machine. Clarke also collaborated with a UK mass spectrometer company to make a commercially produced mass spectrometer available to the global scientific community.

In his early career, Clarke contributed to the study of meteorites and nuclear physics using isotope mass spectrometry. Beginning in 1969 Clarke published a series of groundbreaking papers on ${ }^{3} \mathrm{He} /{ }^{4} \mathrm{He}$ measurements in seawater and lakes (Clarke et al., 1969, 1970; Clarke and Kugler, 1973; Craig and Clarke, 1970; Craig et al., 1975; Jenkins and Clarke, 1976; Top and Clarke, 1983; Torgersen and Clarke, 1985). He contributed research to geology, hydrology, limnology, nuclear physics, medicine, and other disciplines and was active until 2002 publishing on ${ }^{3} \mathrm{He}$-related evidence for and against cold fusion (Clarke, 2001; Clarke and Oliver, 2003; Clarke et al., 2001).

In addition to developing a mass spectrometer capable of measuring ${ }^{3} \mathrm{He} /{ }^{4} \mathrm{He}$ ratios to order $0.1 \%$ on sub-nanomolar gas samples, Clarke also created a method to measure environmental levels of tritium $\left({ }^{3} \mathrm{H}\right)$ in water samples by the ${ }^{3} \mathrm{He}$ regrowth technique (Clarke et al., 1976), which has become the de facto state of the art in low-level tritium measurements. In addition to being intrinsically simpler than the traditional low-level method (which involved electrolytic enrichment combined with low-level proportional gas counting), this method has proved to be more precise (by more than a factor of 4) and extended the detection limit to lower levels (by as much as an order of magnitude) (Bayer et al., 1989; Jenkins et al., 1983; Lott and Jenkins, 1998).

Clarke was inventive and ingenious in the laboratory with a remarkable ability to recognize opportunities where no one else could and to pursue them to ultimate success. He was an accomplished glass blower and constructed vacuum lines and research apparatuses from scratch using many different kinds of glass (see Fig. 10). Clarke kept unusual work hours when not teaching, generally arriving at the laboratory after lunchtime and toiling into the night. Working with him was a delight due to his good nature and whimsical sense of Irish humor but sometimes challenging because he was an inveterate prankster.

\subsection{H. Göte Östlund (1923-2016)}

Östlund was a pioneer in US ocean tracer measurements, establishing a world-class, low-level counting laboratory ded-

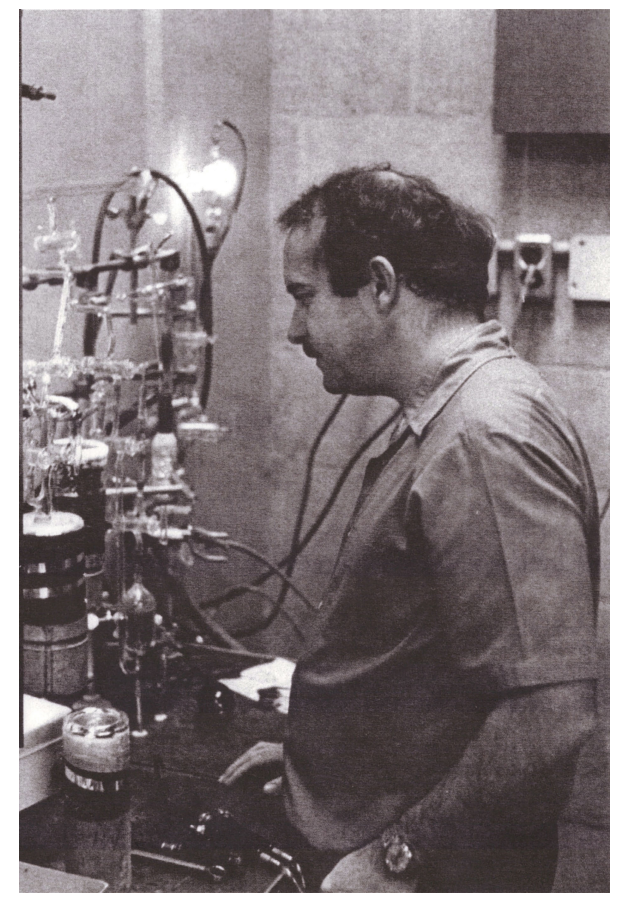

Figure 10. W. Brian Clarke, working on a high vacuum helium extraction apparatus (early 1970s).

icated to the measurement of tritium and radiocarbon at the University of Miami. He made distinguished contributions to ocean, atmosphere, and groundwater sciences, in particular to the understanding of the timescales of the transport of fluids through these systems. Östlund had a life-long devotion to the high-quality measurement of radioactive species. He received a BS in chemistry in 1949 and a $\mathrm{PhD}$ in chemistry in 1958. Both were from the University of Stockholm. Between 1959 and 1961 Östlund developed the electrolytic enrichment of tritium and deuterium for low-level environmental tritium measurements by gas proportional counting at the Radioactive Dating Laboratory of the Swedish Geological Survey. In the early 1960s, he came to the Rosenstiel School of the University of Miami. At the Rosenstiel School, he built a world-class tritium and radiocarbon counting laboratory that set new standards for low-level counting. His laboratory also processed the samples rapidly, and he generously shared his data with colleagues. As a result, relatively routine collection and analysis of large quantities of samples in a timely manner enabled oceanographers to use the tracer data to gain new insights into the timescales of oceanographic processes. His work paved the way for the acceptance of the next generation of tracer oceanographers, those measuring tritium and helium- 3 by mass spectrometry and those measuring the chlorofluorocarbons. 


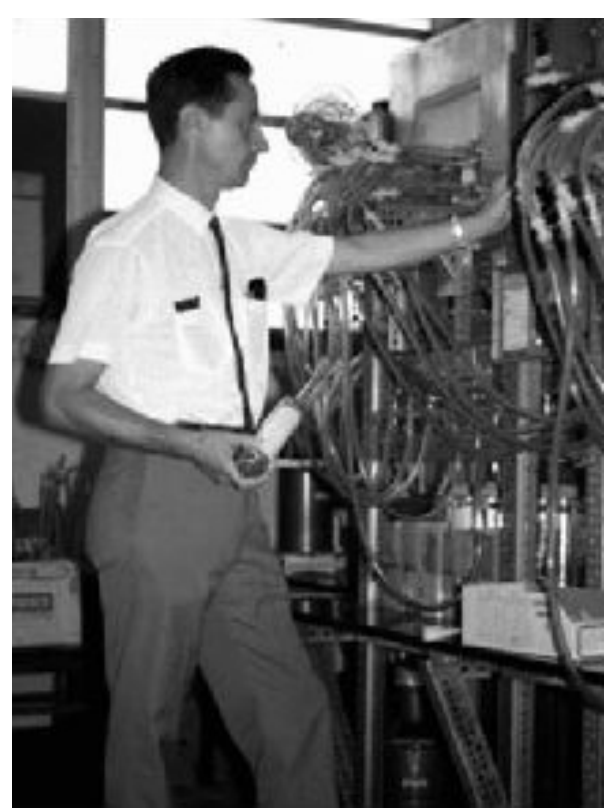

Figure 11. H. Göte Östlund preparing a gas sample for low-level counting analysis (mid-1960s).

He played a key role in the creation and execution of early global ocean survey programs. He developed electrolytic enrichment techniques for low-level environmental tritium measurements by gas proportional counting (see Fig. 11).

Östlund was a member of the scientific steering committee for the Geochemical Ocean Sections Study (GEOSECS), which was the first global-scale survey of chemical, isotopic, and radiochemical tracers in the ocean (1972-1978). He produced the first large-scale, high-quality mapping of the distribution of tritium in the oceans, which opened oceanographers' eyes to the dynamic and rapid penetration of bombproduced tracers into the deep ocean.

Östlund published over 100 papers in peer-reviewed journals on a wide range of subjects. Although his early interests focused on many areas including atmospheric transport, they quickly extended to the hydrologic cycle and the ocean for which he applied radioactive tracers to a spectrum of scientific problems. As a student, he participation in the discovery of the anaesthetic Xylocain. Soon after coming to Miami, he used tritium to show that evaporation from the ocean is the major energy source for hurricanes. To collect samples he even flew into the eye of a hurricane. He and a colleague were the first to use tritium data to show that vertical mixing in the upper layers of the open ocean was an order of magnitude smaller than predicted by mass balance and theory. This was corroborated 20 years later by other investigators using new techniques. A major interest of his was the Arctic Ocean. There he quantified the contributions from ice melt, runoff, and precipitation to the freshwater budget. This budget plays a critical role in the global overturning circulation, which is the leading candidate for modulating decadal to centennial climate.

Östlund was involved in the planning and implementation and served on the scientific steering committees of early global change programs: Geochemical Ocean Sections (GEOSECS), which was the first global-scale survey of chemical, isotopic, and radiochemical tracers in the ocean (1972-1978), followed in the 1980s by Transient Tracers in the Oceans (TTO). The data his laboratory produced and collected under the auspices of these programs have furthered our understanding of the timescales of ocean processes. For example, the data have been used to estimate the flux of anthropogenic carbon dioxide into the ocean, the rate of exchange between the atmosphere and ocean, and rates of deepwater formation. He produced the first large-scale, highquality mapping of the distribution of tritium in the ocean, which opened a new vista on the dynamic and rapid penetration of bomb-produced tracers into the deep western North Atlantic Ocean. Östlund's leadership as a member and coordinator of the scientific advisory committee for GEOSECS and TTO and his vision and credibility in seeing that an accelerator mass spectrometry facility for ${ }^{14} \mathrm{C}$ analysis was established in the USA - had a large influence on ocean science. The big oceanographic programs of the past 50 years (GEOSECS through WOCE, CLIVAR, and GO-SHIP) have provided platforms for obtaining large quantities of highquality tracer data.

Östlund was soft-spoken and gentle in demeanor and generous with his time, advice, and data. He set an example and benchmark for subsequent generations of tracer geochemists for responsibility, honesty, and fairness.

Author contributions. WJJ is responsible for most of the writing of this article, along with preparation of the figures and assembly and quality control of the data in various formats. Numerous co-authors provided useful ideas, discussion, and critical review of the manuscript, including SCD, RK, WR, and RN. Several authors pointed out and provided missing data, including PJB, RK, BK, and MR. MF provided early compilations of the data. RF provided helpful background information on H. Göte Östlund.

Competing interests. The authors declare that they have no conflict of interest.

Acknowledgements. This synthesis work was funded under the auspices of a U.S. National Science Foundation grant number OCE1434000. Financial support for the actual measurements came from a wide variety of different research grants from many agencies in many countries, far too numerous to list here. William J. Jenkins is grateful to a number of US funding sources, most notably the National Science Foundation, NOAA, DOE, and ONR. 
Review statement. This paper was edited by Giuseppe M. R. Manzella and reviewed by two anonymous referees.

\section{References}

Aldrich, L. T. and Nier, A. O.: The occurrence of ${ }^{3} \mathrm{He}$ in natural sources of helium, Phys. Rev., 74, 1590-1594, 1948.

Bainbridge, A. E., Sandoval, P., and Suess, H. E.: Natural tritium measurements by ethane counting, Science, 134, 552-553, 1961.

Bainbridge, A. E., Östlund, H. G., Craig, H., Broecker, W. S., and Spencer, D. W.: GEOSECS Atlantic, Pacific, and Indian Ocean Expeditions: Shore-based data and graphics, GEOSECS ATLAS, National Science Foundation, Washington, D.C., USA, 1987.

Bayer, R., Schlosser, P., Bonisch, G., Rupp, H., Zaucker, F., and Zimmek, G.: Performance and blank components of a mass spectrometric system for routine measurement of helium isotopes and tritium by ${ }^{3} \mathrm{He}$ ingrowth method, Sitzungberichte der Heidelberger Akademie der Wissenschaften, Mathematischnaturwissenschaftliche Klasse, 5, 241-279, 1989.

Bianchi, D., Sarmiento, J. L., Gnanadesikan, A., Key, R. M., Schlosser, P., and Newton, R.: Low helium flux from the mantle inferred from simulations of oceanic helium isotope data, Earth Planet. Sc. Lett., 297, 379-386, 2010.

Broecker, W. S., Sutherland, S. C., and Smethie, W. M.: Oceanic radiocarbon: separation of the natural and bomb components, Global Biogeochem. Cy., 9, 263-288, 1995.

Brown, K., Dingley, K. H., and Turteltaub, K. W.: Accelerator mass spectrometry for biomedical research, Method. Enzymol., 402, 423-443, 2005.

Cameron, J. F.: Radioactive dating and methods of low-level counting, Proceedings of "Radioactive Dating and Methods of LowLevel Counting", International Atomic Energy Agency, Monaco, 2-10 March 1967, 543-574, 1967.

Chiarappa-Zucca, M. L., Dingley, K. H., Roberts, M. L., Velsko, C. A., and Love, A. H.: Sample preparation for quantification of tritium by acclerator mass spectrometry, Anal. Chem., 74, 62856290, 2002.

Clarke, W. B.: Search for ${ }^{3} \mathrm{He}$ and ${ }^{4} \mathrm{He}$ in Arata-Style Palladium Cathods I: a negative result, Fusion Sci. Technol., 40, 147-151, https://doi.org/10.13182/FST01-A189, 2001.

Clarke, W. B. and Kugler, G.: Dissolved helium in groundwater: a possible method for uranium and thorium prospecting, Econ. Geol., 68, 243-251, 1973.

Clarke, W. B. and Oliver, B. M.: Response to "Comments on 'Search for ${ }^{3} \mathrm{He}$ and ${ }^{4} \mathrm{He}$ in Arata-style palladium cathodes I: a negative result' and 'Search for ${ }^{3} \mathrm{He}$ and ${ }^{4} \mathrm{He}$ in Arata-style palladium cathodes II: evidence for tritium production"', Fusion Sci. Technol., 43, 135-136, 2003.

Clarke, W. B., Beg, M. A., and Craig, H.: Excess ${ }^{3}$ He in the sea: evidence for terrestrial primordial helium, Earth Planet. Sc. Lett., 6, 213-220, 1969.

Clarke, W. B., Beg, M. A., and Craig, H.: Excess Helium 3 at the North Pacific GEOSECS station, J. Geophys. Res., 75, 76767678, 1970.

Clarke, W. B., Jenkins, W. J., and Top, Z.: Determination of tritium by spectrometric measurement of ${ }^{3} \mathrm{He}$, Int. J. Appl. Radiat. Is., 27, 515-525, 1976.
Clarke, W. B., Oliver, B. M., McKubre, M. C. H., Tanzella, F. L., and Tripodi, P.: Search for ${ }^{3} \mathrm{He}$ and ${ }^{4} \mathrm{He}$ in Arata-Style Palladium Cathodes II: Evidence of tritium production, Fusion Sci. Technol., 40, 152-167, https://doi.org/10.13182/FST01-A190, 2001.

Cornog, R. and Libby, W. F.: Production of radioactive hydrogen by neutron bombardment of boron and nitrogen, Phys. Rev., 59, p. 1046, 1941.

Craig, H. and Clarke, W. B.: Oceanic ${ }^{3} \mathrm{He}$ : contribution from cosmogenic tritium, Earth Planet. Sc. Lett., 9, 45-48, 1970.

Craig, H., Clarke, W. B., and Beg, M. A.: Excess ${ }^{3}$ He in deep water on the East Pacific Rise, Earth Planet. Sc. Lett., 26, 125-132, 1975.

Currie, L. A., Libby, W. F., and Wolfgang, R. L.: Tritium production by high energy protons, Phys. Rev., 101, 1557-1563, 1956.

Doney, S. C. and Jenkins, W. J.: Ventilation of the deep western boundary current and abyssal Western North Atlantic: Estimates from tritium and ${ }^{3} \mathrm{He}$ distributions, J. Phys. Oceanogr., 24, 638659, 1994.

Doney, S. C., Glover, D. M., and Jenkins, W. J.: A model function of the global bomb-tritium distribution in precipitation, 1960-1986, J. Geophys. Res., 97, 5481-5492, 1992.

Dorsey, H. G. and Peterson, W. H.: Tritium in the Arctic Ocean and East Greenland Current, Earth Planet. Sc. Lett., 32, 342-350, 1976.

Dreisigacker, E. and Roether, W.: Tritium and ${ }^{90} \mathrm{Sr}$ in North Atlantic surface water, Earth Planet. Sc. Lett., 38, 301-312, 1978.

Fine, R. A. and Östlund, H. G.: Source function for tritium transport models in the Pacific, Geophys. Res. Lett., 4, 461-464, 1977.

Fine, R. A., Reid, J. L., and Östlund, H. G.: Circulation of tritium in the Pacific Ocean, J. Phys. Oceanogr., 11, 3-14, 1981.

Fine, R. A., Peterson, W. H., and Östlund, H. G.: The penetration of tritium into the tropical Pacific, J. Phys. Oceanogr., 17, 553-564, 1987.

Fuchs, G., Roether, W., and Schlosser, P.: Excess ${ }^{3} \mathrm{He}$ in the ocean surface layer, J. Geophys. Res., 92, 6559-6568, 1987.

German, C. R., Casciotti, K. L., Dutay, J.-C., Heimburger, L. E., Jenkins, W. J., Measures, C., Mills, R. A., Obata, H., Schlitzer, R., Tagliabue, A., Turner, D. R., and Whitby, H.: Hydrothermal impacts on trace element and isotope ocean biogeochemistry, Philos. T. Roy. Soc. A, 374, 20130035, https://doi.org/10.1098/rsta.2016.0035, 2016.

Glagola, B. G., Phillips, G. W., Marlow, K. W., Myers, L. T., and Omohundro, R. J.: Low level tritium detection using accelerator mass spectrometry, Nucl. Instrum. Meth. B, 5, 221-225, 1984.

Grosse, A. V., Johnston, W. M., Wolfgang, R. L., and Libby, W. F.: Tritium in nature, Science, 113, 1-2, 1951.

Holzer, M., DeVries, T., Bianchi, D., Newton, R., Schlosser, P., and Winckler, G.: Objective estimates of mantle ${ }^{3} \mathrm{He}$ in the ocean and implications for constraining the deep ocean circulation, Earth Planet. Sc. Lett., 458, 305-314, 2017.

Israel, G. W.: Messung des Tritium-Jahresganges im Regen 19601961 nach Isotopenanreicherung im Trnnrohr, Z. Naturforschg., 17a, 925-929, 1962.

Jenkins, W. J.: Tritium-helium dating in the Sargasso Sea: a measurement of oxygen utilization rates, Science, 196, 291-292, 1977.

Jenkins, W. J.: ${ }^{3} \mathrm{H}$ and ${ }^{3} \mathrm{He}$ in the Beta Triangle: Observations of gyre ventilation and oxygen utilization rates, J. Phys. Oceanogr., 17, 763-783, 1987. 
Jenkins, W. J.: Nitrate flux into the euphotic zone near Bermuda, Nature, 331, 521-523, 1988.

Jenkins, W. J.: Studying Thermocline Ventilation and Circulation Using Tritium and ${ }^{3} \mathrm{He}$, J. Geophys. Res., 103, 15817-15831, 1998.

Jenkins, W. J. and Clarke, W. B.: The distribution of ${ }^{3} \mathrm{He}$ in the western Atlantic Ocean, Deep-Sea Res., 23, 481-494, 1976.

Jenkins, W. J. and Doney, S. C.: The Subtropical Nutrient Spiral, Global Biogeochem. Cy., 17, 1110, https://doi.org/10.1029/2003GB002085, 2003.

Jenkins, W. J. and Rhines, P. B.: Tritium in the deep North Atlantic Ocean, Nature, 286, 877-880, 1980.

Jenkins, W. J. and Smethie, W. M.: Transient tracers track ocean climate signals, Oceanus, 39, 29-32, 1996.

Jenkins, W. J., Beg, M. A., Clarke, W. B., Wangersky, P. J., and Craig, H.: Excess ${ }^{3} \mathrm{He}$ in the Atlantic Ocean., Earth Planet. Sc. Lett., 16, 122-130, 1972.

Jenkins, W. J., Edmond, J. M., and Corliss, J. B.: Excess ${ }^{3} \mathrm{He}$ and ${ }^{4} \mathrm{He}$ in Galapagos submarine hydrothermal waters, Nature, 272, 156-158, 1978.

Jenkins, W. J., Lott, D. E., Pratt, M. W., and Boudreau, R. D.: Anthropogenic tritium in South Atlantic bottom water, Nature, 305, 45-46, 1983.

Jenkins, W. J., Lott, D. E. I., German, C. R., Cahill, K. L., Goudreau, J., and Longworth, B. E.: The deep distributions of helium isotopes, radiocarbon, and noble gases along the U.S. GEOTRACES East Pacific zonal transect (GP16), Mar. Chem., 201, 167-182, 2018a.

Jenkins, W. J., Doney, S. C., Fendrock, M. A., Fine, R. A., Gamo, T., Jean-Baptiste, P., Key, R. M., Klein, B., Lupton, J. E., Rhein, M., Roether, W., Sano, Y., Schlitzer, R., Schlosser, P., Swift, J. H.: A comprehensive global oceanic dataset of discrete measurements of helium isotope and tritium during the hydrographic cruises on various ships from 1952-10-21 to 2016-01-22 (NCEI Accession 0176626). Version 2.2. NOAA National Centers for Environmental Information, Dataset, https://doi.org/10.25921/c1sn9631, 2018b.

Kaufman, S. and Libby, W. F.: The natural distribution of tritium, Phys. Rev., 93, 1337-1344, 1954.

Kurz, M. D. and Jenkins, W. J.: The distribution of helium in oceanic basalt glasses, Earth Planet. Sc. Lett., 53, 41-54, 1981.

Kurz, M. D., Jenkins, W. J., and Hart, S. R.: Helium isotopic systematics of oceanic islands and mantle heterogeneity, Nature, 297, 43-47, 1982.

Libby, W. F.: Atmospheric helium three and radiocarbon from cosmic radiation, Phys. Rev., 59, 671-672, 1946.

Lott, D. E.: Improvements in noble gas separation methodology: a nude cryogenic trap, Geochem. Geophy. Geosy., 2, 2001GC000202, https://doi.org/10.1029/2001GC000202, 2001.

Lott, D. E. and Jenkins, W. J.: An automated cryogenic charcoal trap system for helium isotope mass spectrometry, Rev. Sci. Instrum., 55, 1982-1988, 1984.

Lott, D. E. and Jenkins, W. J.: Advances in the analysis and shipboard processing of tritium and helium samples, International WOCE Newsletter, 30, 27-30, 1998.

Ludin, A., Weppernig, R., Bönisch, G., and Schlosser, P.: Mass spectrometric measurement of helium isotopes and tritium, Technical Report No. 98.6, 41 pp., Lamont-Doherty Earth Observatory, Columbia University, New York, USA, 1998.
Lupton, J. E. and Craig, H.: Excess He-3 in oceanic basalts: evidence for terrestrial primordial helium, Earth Planet. Sc. Lett., 26, 133-139, 1975.

Lupton, J. E. and Jenkins, W. J.: Evolution of the South Pacific helium plume over the past 3 decades, Geochem. Geophy. Geosy., 18, 1810-1823, 2017.

Mamyrin, B. A.: Time-of-flight mass spectrometry (concepts, achievements and prospects), Int. J. Mass Spectrom., 206, 251266, 2001.

Mamyrin, B. A., Anufriyev, S. G., Kamenskiy, I. L., and Tolstikhin, I. I.: Determination of the isotopic composition of atmospheric helium, Geochem. Int., 6, 498-505, 1970.

Michel, R. L.: Tritium inventories of the world oceans and their implications, Nature, 263, 103-106, 1976.

Michel, R. L. and Suess, H. E.: Bomb tritium in the Pacific Ocean, J. Geophys. Res., 80, 4139-4152, 1975.

Miyake, Y., Shimada, T., Sugimura, Y., Shigehara, K., and Saruhashi, K.: Distribution of tritium in the Pacific Ocean, Records of Oceanographic Works in Japan, 13, 17-32, 1975.

Momoshima, N., Nakamura, Y., and Takashima, Y.: Vial Effect And Background Subtraction Method In Low-Level Tritium Measurement By Liquid Scintillation-Counter, Int. J. Appl. Radiat. Is., 34, 1623-1626, 1983.

Östlund, H. G.: The residence time of the freshwater component in the Arctic Ocean, J. Geophys. Res., 87, 2035-2043, 1982.

Östlund, H. G. and Werner, E.: The electrolytic enrichment of tritium and deuterium for natural tritium measurements, International Atomic Energy Agency, Vienna, Austria, 95 pp., 1962.

Östlund, H. G., Dorsey, H. G., and Rooth, C. G.: GEOSECS North Atlantic Radiocarbon and Tritium Results, Earth Planet. Sc. Lett., 23, 69-86, 1974.

Resing, J. A., Sedwick, P. N., German, C. R., Jenkins, W. J., Moffett, J. W., Sohst, B. M., and Tagliabue, A.: Basin-Scale transport of hydrothermal dissolved metals across the South Pacific Ocean, Nature, 523, 203-206, 2015.

Rhein, M., Dengler, M., Sultenfuss, J., Hummels, R., HuttleKabus, S., and Bourles, B.: Upwelling and associated heat flux in the equatorial Atlantic inferred from helium isotope disequilibrium, J. Geophys. Res.-Oceans, 115, C08021, https://doi.org/10.1029/2009JC005772, 2010.

Roberts, M. L., Hamme, R. W., Dingley, K. H., Chiarappa-Zucca, M. L., and Love, A. H.: A compact tritium AMS system, Nucl. Instrum. Meth. B, 172, 262-267, 2000.

Roether, W., Well, R., Putzka, A., and Ruth, C.: Component separation of oceanic helium, J. Geophys. Res., 103, 27931-27946, 1998.

Roether, W., Vogt, M., Vogel, S., and Sültenfuß, J.: Combined sample collection and gas extraction for the measurement of helium isotopes and neon in natural waters, Deep-Sea Res. Pt. I, 76, 2734, 2013.

Roshan, S., Wu, J., and Jenkins, W. J.: Long-range transport of hydrothermal dissolved $\mathrm{Zn}$ in the tropical South Pacific, Mar. Chem., 183, 25-32, 2016.

Sarmiento, J. L.: A simulation of bomb tritium entry into the Atlantic Ocean, J. Phys. Oceanogr., 13, 1924-1939, 1983.

Schlitzer, R.: Quantifying He fluxes from the mantle using multitracer data assimilation, Philos. T. Roy. Soc. A, 374, 0000-00023740-6499, https://doi.org/10.1098/rsta.2015.0288, 2016. 
Stanley, R. H. R., Jenkins, W. J., Doney, S. C., and Lott III, D. E.: The ${ }^{3} \mathrm{He}$ flux gauge in the Sargasso Sea: a determination of physical nutrient fluxes to the euphotic zone at the Bermuda Atlantic Time-series Site, Biogeosciences, 12, 51995210, https://doi.org/10.5194/bg-12-5199-2015, 2015.

Top, Z. and Clarke, W. B.: Helium, neon, and tritium in the Black Sea, J. Mar. Res., 41, 1-17, 1983.

Torgersen, T. and Clarke, W. B.: Helium accumulation in groundwater, 1: an evaluation of sources and the continental flux of crustal He-4 in the Great Artesian Basin, Australia, Geochim. Cosmochim. Ac., 49, 1211-1218, 1985.

Unterweger, M. P., Coursey, B. M., Schima, F. J., and Mann, W. B.: Preparation and calibration of the 1978 National Bureau of Standards tritiated-water standards, Int. J. Appl. Radiat. Is., 31, 611-614, 1980.
Weiss, R. F.: Piggyback sampler for dissolved gas studies on sealed water samples, Deep-Sea Res., 15, 695-699, 1968.

Weiss, W. M. and Roether, W.: The rates of tritium input to the world oceans, Earth Planet. Sc. Lett., 49, 435-446, 1980.

Weiss, W. M., Roether, W., and Dreisigacker, E.: Tritium in the North Atlantic: inventory, input and transfer to the deep water, in: The Behavior of tritium in the Environment, International Atomic Energy Agency, Vienna, Austria, 1979.

Young, C. and Lupton, J. E.: An ultratight fluid sampling system using cold-welded copper tubing., EOS Transactions AGU, 64, p. $735,1983$. 